This item was submitted to Loughborough's Research Repository by the author.

Items in Figshare are protected by copyright, with all rights reserved, unless otherwise indicated.

\title{
The language of critical discourse analysis: the case of nominalization
}

PLEASE CITE THE PUBLISHED VERSION

http://dx.doi.org/10.1177/0957926508095894

PUBLISHER

(c) Sage

VERSION

AM (Accepted Manuscript)

LICENCE

CC BY-NC-ND 4.0

REPOSITORY RECORD

Billig, Michael. 2019. "The Language of Critical Discourse Analysis: The Case of Nominalization”. figshare. https://hdl.handle.net/2134/13361. 
This item was submitted to Loughborough's Institutional Repository (https://dspace.lboro.ac.uk/) by the author and is made available under the following Creative Commons Licence conditions.

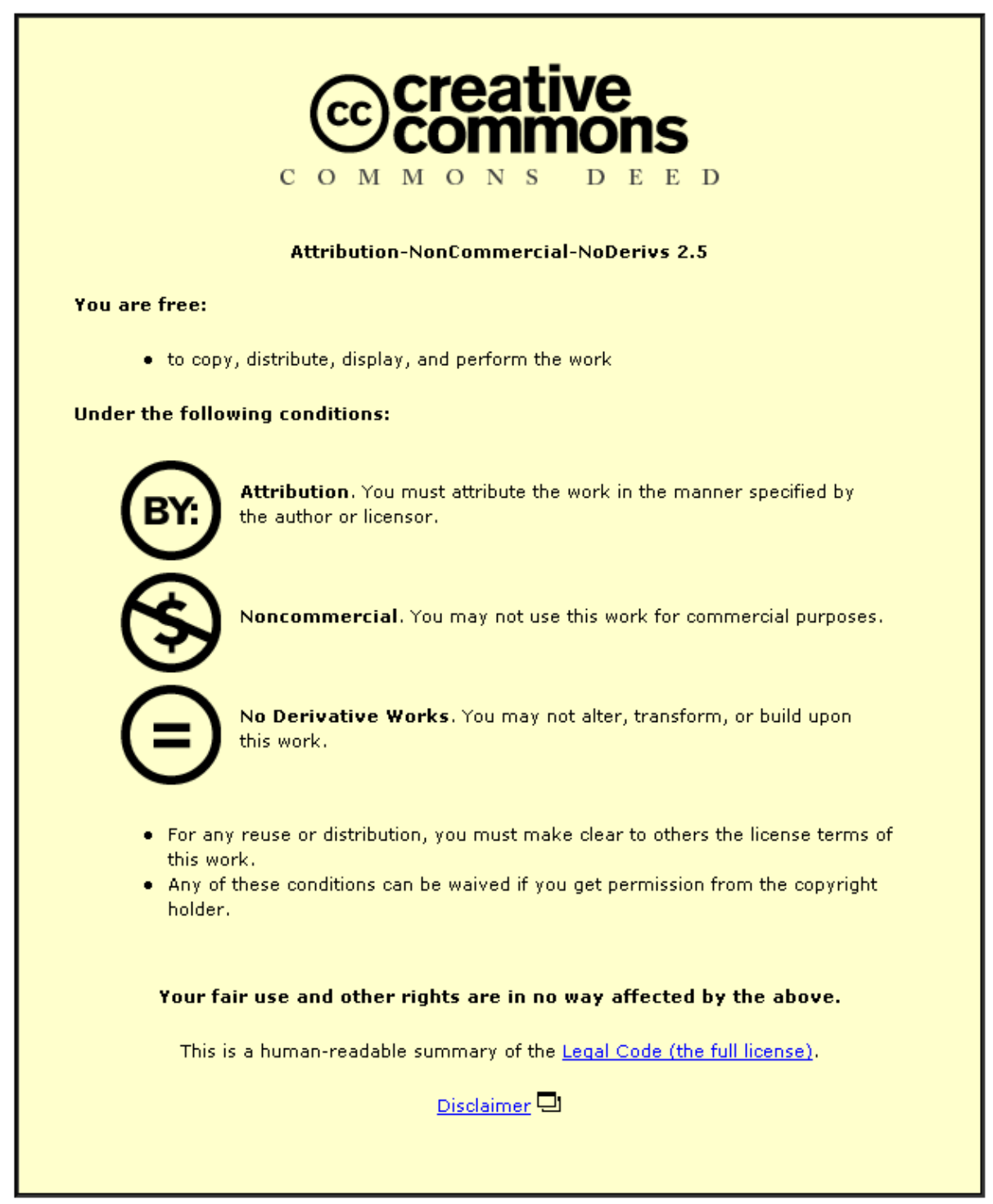

For the full text of this licence, please go to: http://creativecommons.org/licenses/by-nc-nd/2.5/ 
The Language of Critical Discourse Analysis: the case of nominalization

Michael Billig

Department of Social Sciences

Loughborough University

Loughborough, LE11 3TU

United Kingdom 


\begin{abstract}
This article examines the way that critical discourse is written. It does so by considering the concept of nominalization. Critical discourse analysts have suggested that nominalization (along with passivization) has important ideological functions such as deleting agency and reifying processes. However, the language used by critical analysts, as they explore nominalization, is revealing. They tend to use, and thereby instantiate, the very forms of language whose ideological potentiality they are warning against - such as deleting agency, using passives and turning processes into entities. The concept of 'nominalization' is itself a nominalization; it is typically used in imprecise ways that fail to specify underlying processes. If critical analysts take seriously their own ideological warnings about nominalization and passivization, they need to change the standard ways of writing critical analysis. We need to use simpler, less technical prose that clearly ascribes actions to human agents.
\end{abstract}

Key words: nominalization, passivization, jargon, critical analysis, writing style 
All discourse analysts face a paradoxical situation. We investigate language, yet at the same time we must use language in order to make our investigations. We have no separate tools to pursue our tasks. Discourse analysis does not, and cannot, exist outside of language: it comprises articles, books, talks etc. We cannot, therefore, rigidly separate the objects of our analyses from the means by which we conduct our analyses. The problem is particularly acute for critical discourse analysts. We seek to analyse language critically, exposing the workings of power and ideology within the use of language. But how can we do this, if we have to use language in order to make our critical analyses? How can we be sure that our own use of language is not marked, even corrupted, by those ideological factors that we seek to identify in the language of others?

This is an inescapable problem which critical discourse analysts should bear in mind particularly as Critical Discourse Analysis (CDA) is becoming established as a successful, academic sub-speciality. With success there inevitably comes criticism. Of course, CDA's traditional critics continue with their attacks (e.g., Widdowson, 2004), but, as Beaugrande (2006) notes, some left-wing critics have recently been questioning the value of CDA. In addition, some critical discourse analysts have been engaging is self-critique. That is not surprising. If critical discourse analysts are to be fully 'critical', they should not be shy of critically examining the successful emergence of CDA and other critical studies (Billig, 2000, 2003; and, more generally, 2008). Chilton (2005), who has contributed much to the development of CDA, questions what CDA has actually contributed to our understanding of the practice of language. As Wodak (2006) suggests, there is plenty of scope for fruitful, productive debate.

Accordingly, critical discourse analysts should be particularly concerned to examine their own use of language. How to write CDA is much more than an issue of style. It should be a major issue for analysts who stress the pivotal role of language in the reproduction of ideology, inequality and power. In discussing this, it is important to examine how critical analysts actually use language, rather than writing in general, theoretical terms.

Therefore, in this paper I will try to identify and analyse a particular phenomenon: namely, critical analysts instantiating in their own writings the same linguistic forms that they criticise in the language of others.

This occurs when analysts are critically examining a particular form of discourse/syntax/semantics and they themselves use that particular form - not as an example, but as part of their analysis. In so doing, they provide an instance of the object of analysis within their own analysis of that object. This would not matter greatly if the analyst were providing the instance self-reflectively. It does matter if the analyst seems unaware that they are using the very linguistic forms that they are critically analysing. If critical analysts use the same forms of language, whose ideological biases they are exposing in others, then they might be uncritically and unselfconsciously instantiating those very biases. 


\section{Nominalization and Passivization}

In order to prevent the discussion about instantiating objects of analysis from becoming too diffuse, I will concentrate on the ways that leading critical discourse analysts have discussed 'nominalization', and, to a lesser extent, 'passivization'. Both concepts have been enormously important in the development of Critical Discourse Analysis, especially in the early work Roger Fowler and the East Anglian School. Teun van Dijk has recently identified Language and Social Control (Fowler et al, 1979) as the seminal book which really introduced CDA (van Dijk, 2007: xxiv-xxv). In that work, Fowler and his coworkers built upon the linguistic ideas of Michael Halliday in order to demonstrate how the details of texts can serve to reproduce the workings of ideology. Although critical discourse analysts today are less reliant on the grammar of Halliday, the early work of Fowler and his colleagues has remained a major and continuing influence (Fairclough, 2005; van Dijk, 2001b; Wodak, 2006, 2007).

The analysis of 'nominalization' was one of the most exciting features of the early work. By examining a series of examples, Fowler et al (1979) demonstrated that choosing noun phrases over verbs and the passive voice over active voice was often ideologically charged. Their work, together with the classic work of Fowler (1991), transformed our understanding of common discursive phenomena such as newspaper headlines. Most readers of Language and Social Control would afterwards find it difficult to view headlines such as 'Attack on Protestors' as innocent summaries of reported stories. The East Anglian Group pointed out that such headlines systematically omitted the agents of the action. In this case, the agents would be the people who were attacking the protestors. A headline writer could omit this information by using a noun such as 'attack', or by using a passive verb: 'Protestors Attacked'. A sentence, which used 'attack' as an active verb, would need to identify who was doing the attacking: e.g. 'Police Attack Protestors'. Fowler and his colleagues persuasively argued that in these contexts the choice of passive over active, or of noun over verb, was not ideologically random.

Fowler and colleagues bracketed together the producing of nouns/noun phrases, or nominalization, with the producing of passive constructions or 'passivization'. They took both concepts - nominalization and passivization - from linguistics. Significantly, Fowler and colleagues described both as processes or transformations. Nominalization was, for instance, 'turning verbs into nouns' (Fowler et al: 14). It was a 'process of syntactic reduction' (p. 41, emphasis added). They wrote: 'nominalization is a transformation which reduces a whole clause to its nucleus, the verb, and turns that into a noun' (p. 39). The significance of describing nominalization and passivization as processes or transformations will, it is hoped, become clearer later on.

The East Anglian group and subsequent analysts emphasised that there are several ideological features associated with nominalization and passivization: (a) deleting agency; (b) reifying; (c) positing reified concepts as agents; (d) maintaining unequal power relations. 
(a) Deleting agency. As has been mentioned, the East Anglian group argued that if speakers/writers used nominalization or passivization, they can transform statements that identified agents of actions into agentless statements that convey less information. The linguist, Ronald Langacker (1999) has described nominalization as an asymmetric process. While a sentence that describes an agent performing an act can be easily transformed by nominalization into a statement about the act, the reverse is not true. 'Police attack protestors' can be easily transformed by anyone with a knowledge of the syntactic rules of English into 'An attack on protestors occurred'. However, knowledge of the linguistic rules of syntactic transformation does not enable the native speaker to construct the former sentence from the latter, because nominalization has ensured that the latter sentence contains less information than the former.

(b) Reifying. By turning verbs into nouns, speakers/writers can convey that the entities, denoted by nominalization, have a real and necessary existence. Hallidayan grammar distinguishes processes and entities. In general terms, by means of nominalization speakers/writers turn processes into entities and typically assume the existence of such entities. Fowler (1991) writes that by means of nominalization 'processes and qualities assume the status of things: impersonal, inanimate, capable of being amassed and counted like capital, paraded like possessions' (p. 80). These linguistically created things have a privileged discursive status because of their presumed existence (see also, Moltmann, 2007). As Halliday and Martin (1993) have commented, the presuppositions that justify the existence of these entities are harder to contest because 'you can argue with a clause but you can't argue with a nominal group' (p. 39). Fowler et al (1979) note that official discourse often uses nominalizations in this way, thereby conveying that present social arrangements are objective, unchangeable things. Muntigl (2002) and Mautner (2005) have examined how writers on economics can use nominalization to imply economic processes, such as 'market forces', are 'objective things' rather than the contingent results of human actions.

(c) Positing reified concepts as agents. Speakers/writers can then use the abstract, reified concepts as agents of processes. Instead of talking about people buying and selling commodities for various prices, economists, administrators, journalists etc might talk about 'market-forces'. The nominal term 'market-forces' can then be used as the subject for verbs that denote agency: 'market-forces dictate/demand/forbid...' etc (see also Fairclough, 2003: 143ff; Stenvall, 2007). This completes the transformation of processes into entities: these nominalized entities then become posited as the agents of processes.

(d) Maintaining unequal power relations. The East Anglian Group claimed that it was no accident that the writers of formal documents tended to use nominalization and passivization. Fowler et al wrote about the relations between 'nominalization' and 'lexicalization': new lexical terms can be created through nominalizing verbs. Technical and scientific writers often use nominalization in this way. The effect of creating new terms often 'is control through the one-way flow of knowledge' (Fowler et al, 1979: 33). Halliday and Martin (1993) make a similar point in their analysis of the language of science. Scientists use technical language which is filled with nominalizations rendering processes as entities. Those, who create and use this specialised language, act as the 
gatekeepers for the scientific community, ensuring that young researchers write in the appropriate way. As such, formal discourse belongs to, and helps reproduce, a social context of inequality.

Given these four properties, it is no surprise that Fowler et al (1979) warned that nominalization and passivization, especially when used by official speakers/writers, lent themselves to ideological uses. Fowler (1991), referring to the argument of Language and Social Control, commented that 'we claimed nominalization was inherently potentially mystificatory; and that it permitted habits of concealment' (p. 80).

Problems with the Ideological Analysis of Nominalization

Although the work of the East Anglian group has had a decisive impact on Critical Discourse Analysis, some analysts have found problems with their work on nominalization. For example, some critics have suggested that in certain contexts it is by no means mystificatory to use nominalization (e.g., Malrieu, 1999). Instead of listing all possible problems, I will focus on two themes, which are relevant to the issue of instantiating the objects of analysis.

The first theme is the assumption that some forms of description are more congruent than others. Points (a) and (b) suggest that there are more and less 'natural' syntactic forms for particular sorts of description. Halliday's Introduction to Functional Grammar claimed that some descriptions were 'congruent' as compared with others that were 'metaphorical' (see, for instance, Halliday, 1985: 321ff). Fairclough (2003), who criticises the notion of congruency, succinctly summarises what it means in relation to describing entities and processes: 'Entities, things (as well as persons) are congruently represented linguistically as nouns, whereas processes are congruently represented linguistically as verbs with associated subjects, objects and so forth' (p. 143). According to Halliday and Martin (1993) modern sciences and social sciences often fail to use congruent language, because scientific writers use nominalization routinely to treat processes as if they were entities (but see Goatly, 2007, for an important, extended critique of the notion of congruency).

There is a second line of possible criticism - although critical discourse analysts have tended not to develop it in great detail. Fowler et al (1979) and subsequent analysts describe nominalization as a process - although, as I will suggest, they do not use the concept consistently. However, they do not specify what sort of process nominalization is. If verbs are said to be transformed into nouns, then how, when and by whom is this transformation accomplished? There are several very different transformations which the concept ‘nominalization' can describe:

Linguistic Nominalization. Linguists have often examined the syntactic rules by which competent speakers of a particular language regularly transform verbs into nouns and noun phrases (e.g., Maynard, 1999); 
Etymological Nominalization. Over time a new noun might be derived from a verb and become established as a standard lexical item in the language. Fowler et al are describing this process when they offer as examples of nominalization 'reporting' from 'to report', and 'reference' from 'to refer' (see Fowler et al, 1979: 14).

Psychological Nominalization. This would be a supposed cognitive process, which would occur if speakers/writers spontaneously (and congruently) think in terms of noun/active-verb sentences, and then transform these thoughts by nominalization when they come to express them.

Between-Text Nominalization. This occurs when one text uses noun/active-verb descriptions but the writer of a second text repeats these descriptions, but transforms them through nominalization (see, for example, the study by Kuo and Nakama, 2005).

Within-Text Nominalization. This occurs when a text describes a process in terms of noun/active-verb, but then introduces a noun as a name for such a description and henceforth uses this noun as a way of referring to the process. According to Halliday and Martin (1993) this is a common feature of scientific writing (see also Halliday, 2003: 42ff).

Many critical analysts have retained the general concept of nominalization (and that of passivization) within their critical armoury, despite not distinguishing between the different possible processes for nominalising verbs. Like the East Anglian group, such analysts convey an ideological distrust of nominalization. Recent analysts continue to quote approvingly Fowler's comment about nominalization being potentially mystificatory (e.g., Kuo and Nakamar, 2005: 404; Stenvall, 2007: 210). Likewise Schroder (2002: 105) claims that 'syntactic transformations, particularly those labelled 'passivization' and 'nominalization', can be considered ideologically problematic'.

Describing and Instantiating Nominalization

Readers with a background in CDA will probably have read the quotation from Schroder as a familiar description that scarcely merits examination. But look at it carefully. It warns against 'passivization', calling it problematic. The sentence contains two verbs. Both are in the passive tense: 'labelled' and 'can be considered'. In using them, the writer omits agency - leaving unspecified who does the labelling or who might consider passivization as problematic. By the omission, the writer conveys that everyone might do so. The sentence also warns against 'nominalization'. It uses three words that, at least etymologically, are the products of nominalization: namely, 'transformation', 'passivization' and 'nominalization'. Again agency is omitted. We are not told whose syntactic transformations are problematic; nor are we told how the activity of transforming was accomplished. In short, this familiar type of description seems to instantiate the very linguistic features that it warns against. 
Of course, one quotation proves little. It is necessary to show a pattern. To this end, I will look at some of the classic writings on nominalization by Roger Fowler and his colleagues. I will also examine how one of the most respected figures in CDA, Norman Fairclough, discusses 'nominalization'. My aim is not to subvert their important work; quite the reverse, by taking their ideas of nominalization seriously, I intend to examine how these authors can instantiate the very syntactic forms that they are analytically putting under suspicion.

First, I will give a couple of examples to show that the Schroder quotation is not exceptional. Fowler et al (1979) write that 'in most styles that people find 'formal' and 'impersonal' two syntactic constructions are almost invariably found to be prevalent: nominalization and passivization' (p. 39). The verb 'find' is used twice, once in the active tense. The second use is passive - 'are almost invariably found'. The sentence, like Schroder's uses three nouns that prima facie may have etymologically emerged through by nominalization: construction, nominalization and passivization.

Fairclough (1992: 27), in introducing the concepts of nominalization, writes that 'nominalization is the conversion of a clause into a nominal or noun'. He goes on to say that nominalization, along with 'passivization', 'may be associated with ideologically significant features of texts such as the systematic mystification of agency; both allow the agent of a clause to be deleted'. He uses the passive tense: passivization 'may be associated'. In using the passive tense, he does not specify the agents who might associate nominalization and passivization with ideologically significant features of the text. When he says that these features 'allow the agent of a clause to be deleted', again he uses a passive - 'to be deleted' - which in its turn permits him to delete who might be the agent who is deleting agents. He presents nominalization as a 'conversion'. By using the noun 'conversion', rather than the active tense of the verb 'convert', he need not specify who does the converting or how and when they do it. Fairclough, Fowler and Schroder do not comment that they are using the sort of terms that they are analysing. The indications are that they are instantiating their objects of analysis unselfconsciously.

To give a further example from Fowler et al (1979). They suggest that nominalization can involve the creation of new specialized words or 'relexicalization'. They write:

Many derived nominals can be spotted by their ending in -ion, -ition, - - ation, ience, -ness, -ment, etc...We have already seen that nominalization facilitates relexicalization, the coding of a new, specialised, set of concepts in a new set of lexical terms. (p. 40).

Fowler et al then do not note that the terms they are using to make their analysis 'relexicalization', 'passivization', 'nominalization' - are precisely the sort of terms that they are discussing: derived nominals ending in '-ation'. Their own theoretical terms, to use their own phrase, comprise a specialised set of concepts in a new set of lexical terms. Yet, this is just the sort of language that the authors suggest might be ideologically problematic. 


\section{Nominalization as Process: Fowler}

If Fowler and his colleagues are correct, then nominalization and passivization can function to conceal and this would include their own use of nominalizations. Examples, however, need to be examined in detail. Here is a section from Fowler's Language in the News, in which he discusses nominalization:

Nominalization is a radical syntactic transformation of a clause, which has extensive structural consequences, and offers substantial ideological opportunities. To understand this, reflect on how much information goes unexpressed in a derived nominal, compared with a full clause: compare, for example, 'allegations' with the fully spelt-out proposition ' $\mathrm{X}$ has alleged that $\mathrm{Y}$ did A and that Y did B (etc.)'. Deleted in the nominal form are the participants (who did what to whom?), and indication of time - because there is no verb to be tensed - and any indication of modality - the writer's views as the truth or the desirability of the proposition (see pp. 85-7). In Language and Control, we claimed that nominalization was, inherently potentially mystificatory; that it permitted habits of concealment, particularly in the areas of power-relations and writers' attitudes...If mystification is one potential with nominalization, another is reification. Processes and qualities assume the status of things: impersonal, inanimate, capable of being amassed and counted like capital, paraded like possessions (Fowler, 1991: 80).

The passage describes a number of aspects of nominalization, and, in describing them, it instantiates them. First, Fowler describes nominalization as a process - 'a radical syntactic transformation of a clause'. This characterization is self-referential. A process namely transforming a clause from verb forms into a nominal - is itself described by a nominal ('nominalization'), not a verb form. Fowler is treating nominalization as if it were an entity, rather than an activity. He is not referring to individual speakers/writers engaging in the activity of nominalizing. The verb 'nominalize' does not appear in the quoted passage.

Fowler (1991) writes that nominalization offers opportunities for deleting information, such as information about the participants, time and modality. When speakers/writers use active verb clauses, they typically include such information. In describing this, Fowler uses also phrases that delete the sort of information that would have been included had he used active verbs. Fowler gives the example of a text referring to 'allegations', rather than stating $\mathrm{X}$ alleged that $\mathrm{Y}$ did $\mathrm{A}$. He claims that 'deleted in the nominal form' is information about the participants etc. The phrase 'deleted in the nominal form' is itself a passive. It too deletes: in this case, it contains no information about how the writer in question went about the activity (or process) of deleting information nor when the activity took place.

This goes to the heart of the matter. Critical discourse analysts typically describe nominalization as a process, but they tend to be vague about how the process occurs. Do 
individual speakers/writers engage in nominalization as a psychological process when they use nominal forms? Fowler et al (1979) discuss the example of a writer of regulations who uses the nominal phrase 'take responsibility', rather than the verb 'be responsible for'. They write: 'The effect of this nominalization is to present a complex relation as a simple lexical item, and to introduce the process verb 'take”' (p. 30). Fowler et al add the comment: 'We are not suggesting that the writer of these rules went through this sequence of syntactic changes; 'responsibility' is after all a word which is listed in any dictionary of English’ (p. 30).

The comment is revealing. Fowler et al are denying that the nominalization within the text indicates that the producer of the text actually engaged in the activity of nominalization, thinking first in the active tense and then syntactically transforming the active into a nominal form. They are stating that 'nominalization' does not necessarily refer to a mental process, but they do not indicate what sort of process it might be. Instead, there is a gap. They are claiming that verbs have somehow been transformed into nouns with a loss of information along the way. They describe this process with a noun 'nominalization'. In so doing, they reproduce the process, which they are describing, by avoiding specifying exactly what this process is; how and when it occurs; and most importantly who does it.

In practice, Fowler et al, along with other critical discourse analysts, often use 'nominalization' (and 'passivization') not to describe the process that produces the syntactic forms in a given text, but as a description of the textual entities themselves. When Fowler et al write that in most formal styles, 'two syntactic constructions are almost invariably found to be prevalent: nominalization and passivization' (p. 39, emphasis in original), they are not using 'nominalization' to describe the process of turning of verbs into nouns; they are using 'nominalization' (and 'passivization') to describe particular syntactic forms. In this sense, nominalizations include nouns that have been historically derived from verbs, as in the case of 'allegation' from 'to allege', or 'reference' from 'to refer'. However, the analysts are not examining the historical, or etymological, processes of derivation, or any of the other possible sorts of transformation. Instead, the analyst is examining the semantic effects of these linguistic forms that are taken as completed entities.

The consequence is that analysts, despite defining 'nominalization' as a process, frequently treat it methodologically as a syntactic or grammatical entity, which can be identified alongside linguistic entities, such as nouns, verbs, gerunds, actives etc. For example, van Dijk (2001a) discusses the meaning of various syntactical forms. He includes nominalization in a list of such forms: 'ordering, primacy, pronominal relations, active-passive voice, nominalizations, and a host of other formal properties of sentences and sequences' (p. 107). Typically discourse analysts, including critical analysts, examine the discursive and linguistic features of given texts, rather than examining the processes of producing and consuming texts (see, for instances, the criticisms of Chilton, 2005). In so doing, they treat nominalization as a fixed textual feature. When Biber (1992) examined the number of nominalizations in particular corpuses, he was not studying processes of transformation, but the grammatical properties of those texts (see 
also Bratlinger, 1997; Clark, 2003; Muntigl and Horvath, 2005, van Leeuwen and Wodak, 1999; Yeung, 2007 for more research that treats 'nominalization' as a textual/grammatical entity). In this syntactic sense, the word 'nominalization' is most certainly a nominalization.

In the passage quoted earlier, Fowler (1991) writes that nominalization facilitates 'reification' because processes assume the status of things. Here Fowler is using a nominalization (at least in the sense of a syntactic entity) because he uses the noun form ('reificiation') rather than saying that speakers/writers are reifying when they nominalize. When Fowler and other analysts write in this way, then, according to the force of their own arguments, they are engaged in the activity of reifying. This happens also when they use 'nominalization', which ostensibly describes a process, as the name of a linguistic entity. By using the word 'nominalization' as a nominalization, denoting an entity whose existence is taken for granted, they avoid specifying what sort of process ‘nominalization’ also seems to name.

\section{Nominalization as Process: Fairclough}

At this point, someone might object: 'You have concentrated on the classic work of Fowler et al, but there is little reason for supposing that current work in CDA contains the same features.' In order to deal with such criticism, I will briefly consider how Norman Fairclough treats the concept of nominalization. I will suggest that Fairclough, when he discusses nominalization, like Fowler instantiates the forms he writes about.

As has been mentioned Fairclough (1992) describes nominalization as a process of 'conversion', which permits the deletion of agency. When he describes nominalization, he too deletes agency and uses passive forms. For example, Fairclough (2003) refers to nominalization as involving 'the exclusion of Participants in clauses' (p. 144). He uses a nominal 'exclusion', rather than writing of a writer/speaker 'excluding participants' from clauses. If nominalization is a process, then it is a process that tends linguistically to conceal processes. Thus, Fairclough describes nominalization as 'the conversion of processes into nominals, which has the effect of backgrounding the process itself - its tense and modality are not indicated - and usually not specifying its participants, so that who is doing what to whom is left implicit' (1992, p. 179).

By using nominal terms such as 'conversion', 'transformation' and 'deletion' in this context, Fairclough avoids using phrases that draw attention to the activities that language users must accomplish when they nominalize. He does not say that 'when writers/speakers nominalize, they convert clauses into nouns.' If Fairclough had written that, then a reader might ask how exactly do speakers/writers engage in the activity of converting? What is that they must do? And when must they do it? Instead, it is said that there is a 'conversion of processes into nominals' which, as Fairclough suggests, has the effect of backgrounding the process. The conversion is presented as an existing entity: it has what Wodak (2007) describes as an 'existential presupposition'. Therefore, when Fairclough talks about backgrounding processes, he uses a form of language that itself backgrounds the process by which he has defined the nominal 'nominalization' in terms 
of another nominal, namely 'conversion'. As such, he backgrounds the very process of nominalising, which ostensibly his statement is foregrounding.

According to Fairclough, 'nominalization turns processes and activities into states and objects, and concretes into abstracts' (1992, p. 181). The statement could be read as a description of the way that critical analysts have used 'nominalization' as a concept. They have linguistically turned the process of nominalizing into an object - 'nominalization'. They are vague about the ways speakers/writers accomplish this transformation. They do not typically distinguish between the different forms of transformation that were presented earlier. Analysts then treat nominalization as a syntactic entity that exists in the words of a text, rather than as a process that produces, and thereby stands behind, the syntax of the text.

In this spirit, Fairclough (2003) identifies the word 'destruction' as a nominalization, comparing it with 'is destroyed' or 'was destroyed' (p. 143). The full sentence in which Fairclough (2003) describes the 'exclusion of Participants' is revealing:

'It (nominalization) also may involve the exclusion of Participants in clauses - so in this case none of the process nouns or nominalizations has an agent (what would most commonly be the grammatical subject in a clause)' (pp.143-4).

'Nominalization' here refers to an entity rather than a process. The phrase 'process nouns or nominalizations' suggests that the two terms are equivalent: a nominalization is a noun denoting a process. In other words, the writer is indicating that a nominalization is a lexical entity, rather than an unspecified process that results in the use or creation of a particular sort of noun. This is what Fowler describes as 'reification' or the linguistic creation of a thing. In this case, analysts of nominalization are reifying nominalization as a thing.

\section{The Return of the Agent}

The language of analysts examining nominalization shares a further feature with the characteristics that they identify in ideological language. They claim that ideological language not only deletes the agents of processes through the use of nominalization, but it then ascribes these nominalized processes with agency. Accordingly, nominalized forms become the subjects of active sentences, appearing as the agents who do things. This is reified language: things and abstract entities, not people, perform actions. According to Hallidayan grammar, this is an incongruent use of language. Yet, at the same time, critical discourse analysts sometimes depict language (rather than language-users) as doing things, as if the language, or particular forms of language, is the agent of action. For instance, Fairclough (2003), in his discussion of nominalization, writes that nominalization, through generalization and abstraction, 'can obfuscate agency, and therefore responsibility' (p. 144). Here the writer attributes the action of obfuscating to nominalization. Similarly Fairclough (1993) claims: 'Nominalization turns processes and activities into states and objects, and concretes into abstracts'. Nominalization is 
presented as the actor that transforms processes into objects. The agents, having been deleted, return but they return as linguistic concepts.

Analysts of language often use active verbs that normally attribute agency to humans. We are accustomed to reading about the things that language, discourses and syntactic forms can do - as if they were capable of agency. Critical analysts can use this way of writing even when warning of the ideological dangers of attributing agency to non-agentic entities. Fowler et al (1979), analysing the phrasing of regulations concerning university applications, write that 'the passive structure, allowing agent-deletion, permits a discreet silence about who if anyone might refuse to admit the applicant' (p.41). Fowler (1991) writes that nominalization was potentially mystificatory because 'it permitted habits of concealment' (p. 80). 'Allowing' and 'permitting' are usually activities ascribed to human agents. Here, a grammatical structure is said to permit actions to occur or not occur. The form of wording not only 'permits' agent-deletion but then it ascribes agency for the deleting, not to speakers/writers but to forms of wording.

Jay Lemke (1995) has described this move in his book Textual Politics. He discusses critically the abstract language of scientific reports, which linguistically delete human agents and then present processes as agents or participant in actions:

Other types of Processes tend to be expressed as Participants, in these relations (nominalization). Animate agents, especially the human researchers, tend not to appear. This often results from using agentless passive clause structures. The nominalized processes on the other hand are frequently reified and used as agents in the place of human agents... Nominalization allows an entire activity, a process complete with its typical Participants and Circumstances, to be understood merely by naming it with the process noun (p 60).

Lemke is instantiating the very linguistic constructions that are the objects of critical analysis. He uses passives, as he writes about the role of passives ('to be expressed'; 'are frequently reified'; 'to be understood' etc). His own words do not indicate the agents of the processes that he describes. Who is doing the understanding, the nominalizing, the using passive structures etc? Nominalizations, it is said, are 'used as agents in the place of human agents'. This sentence is phrased in the passive with 'nominalizations' as the grammatical subject. The writer's own choice of phrasing exemplifies the way that writers can delete agency.

Lemke, having written that nominalized processes are used as agents in the place of human agents, instantiates this unselfconsciously in his very next sentence. He writes that 'nominalization allows an entire activity...to be understood'. Here he uses an agentive word 'allows'. Who is allowing an entire activity to be understood? No-one, it appears. 'Nominalization' is grammatically the subject that performs the action of allowing. A nominalized process - the very term 'nominalization' - that is said to allow this to happen. The author does not specify how nominalization might be able to allow or permit occurrences. Nor does the author give any sign that his readers should understand the use of the agentive verb 'allow' metaphorically: there is no additional 'so to speak', or other 
rhetorical device to convey the use of figurative language. Instead, the author presents his words as a straightforward, or literal, description. In this way, Lemke instantiates the very grammatical features of reification as he is describing them.

\section{Edifice of Nouns}

When critical discourse analysts use nominalizations (in the sense of syntactic entities) and passive constructions that do not mention human agents, they are not writing in a particularly unique manner. They are following styles of writing that are common in the sciences and social sciences. Halliday and Martin (1993) argue that nominalization is perennial feature of contemporary scientific writing, as scientists constantly name processes through nominalising verbs. Halliday and Martin also point out that the vast majority of technical terms in the sciences are nouns. Nouns are the key terms in this writing, with the interconnecting verbs semantically downgraded. The resulting prose is an 'edifice of words and phrases' (p. 39).

We can see these features in critical discourse analysis. Authors use technical nouns to describe processes - e.g. nominalization, passivization, perspectivation, genericisation, personalization, etc. The verbs that link these technical nouns are often comparatively vague: 'involves', 'allows', 'permits'. It is as if the verbs are the humble servants who lead out their important, nominalized masters in a parade of technical prose.

The question is not whether critical discourse analysts use technical nouns more than other social scientists, but whether they should be attempting to use them less. Social scientists often justify their use of technical concepts by saying that clearly defined specialist words are more precise than those of ordinary language. To judge by the example of 'nominalization', this justification is not entirely convincing. There is a frequent gap between the way analysts define 'nominalization' as a process of syntactic change and their use the term to denote a syntactic entity. Moreover, the definition is imprecise: analysts do not specify what sort of process they are describing. They then use this technical term in ways that ensure that they do not need to specify the process. Far from using the technical term to explore underlying processes more precisely, they can use the term to give an appearance of precision while skirting over what the processes are.

For a number of reasons, critical analysts should be concerned about their use of technical language. The work of Halliday and others has indicated that technical jargon tends to emerge within, and to sustain, social conditions of inequality. High status scientists ensure that lower status scientists use technical terms appropriately. Writing specifically about nominalization, Lemke (1995: 60) comments:

Discourse types that rely heavily on this strategy divide the world of potential readers into initiates and the uninitiated to a much greater degree than do other kinds of written expository texts... The world of technical discourse is a closed world which admits no criteria of validity outside its own' 
If critical analysts are to take heed of their own analyses, they should worry lest their own use of technical jargon, such as 'nominalization' and 'passivization', belongs to a closed world of the initiated.

Critical discourse analysts should also worry that they might be using the same sort of reifying language that they criticise other social scientists for using. Using this language, writers avoid identifying human agents of actions, transform processes into entities, and then treat these process-entities as if they were the agents of actions. Historically, the analysis of ideology began with the assertion that social analysts should explain social life in terms of the actions of actual people, rather than seeing social actions as determined by theoretical concepts. In The German Ideology, the first book that uses 'ideology' in its modern critical sense, Marx and Engels declared that, in contrast with the German idealists, they 'set out from real, active men, and on the basis of their real life-process we demonstrate the development of the ideological reflexes and echoes of this life-process' (1846/1970: 40). The implication is that it is real humans (men and women) who do things and who produce the illusions and evasions of ideology. If social analysts fail to base their analyses on the study of human actions and life-processes, then they will produce 'ideological echoes’ of social life.

The work of critical discourse analysts has suggested that the language of much contemporary social science is poorly equipped for the task of exploring life-processes. It is weighted towards nominals, with nouns having priority over verbs, entities over processes. Critical discourse analysts have shown how writers, by nominalizing descriptions of processes, can describe human life as if it were agentless. Conservative analysts might not be bothered about their use of such technical jargon. Critical analysts, on the other hand, should be concerned, lest their desire to explore the linguistic processes of ideology results in their instantiating those very processes.

There is a political implication. Critical analysis, if it is to be critical, should have political targets. These targets should not be abstract entities but the actions of actual people or classes of people. It is not language as a system (or discourses or grammar) that we should be seeking to change, but the ways that people use language and the circumstances in which they do so. The problem is not what language does or does not do: it is what people do with language. The demand to start with actual people is as pertinent today as it was over a century and a half ago.

\section{Implications of Unconscious Instantiation}

In the previous sections, I have presented examples showing how critical analysts can instantiate those features of discourse that they are revealing as problematic. I hope to have presented sufficient examples to suggest that this is not the stylistic habit of an individual author, but that it is more general. Of course, the case would be strengthened were there a greater range of examples. Hopefully other analysts will take up these points. 
For now, one key question remains: do the examples, discussed above, refute or support the East Anglian group's ideas on nominalization? The case that they refute the East Anglian group might run as follows. Critical writers have argued that nominalization conceals and distorts. Their argument is made through the use of nominalization. Because it uses forms that are said to distort, the argument must itself be distorted. Thus, the critical argument either destroys itself - or reduces itself to a self-referential paradox. Either way, it is seriously compromised. Long-term opponents of critical discourse analysis might pounce gleefully upon the preceding analyses.

There is, however, another way of looking at the matter. We can accept the basic analyses of Fowler et al about the inherent dangers of nominalization and passivization - about how such forms enable writers/speakers to express less information than using active forms. Indeed, such analyses represent some of the most exciting and provocative work in critical discourse analysis. Having accepted these analyses in general terms, we might then draw conclusions about the ways that we should aspire to write. The examples of authors instantiating what they warn against do not undermine the basic analyses. Rather, they show that writers are not heeding their own warnings, even as they are writing those warnings.

One of the most attractive features of Halliday's approach to language is that he stresses that the users of language have to make choices. 'Discourses', 'grammars', 'lexicalizations', or whatever, do not determine what speakers say or writers write. Language users have to select between options. This is one reason why a critical analysis of language-use needs to be based on a psychology of language users (see, for instance, Billig, 1996; Chilton, 2005; Edwards, 2006; Edwards and Potter, 1993; Potter, 2006). On occasions speakers/writers may find it easier not to consider the range of options that are available to them, but to go along with familiar, linguistic habits. This might be happening with discourse analysts. We have been long accustomed to using standard, academic ways of writing, formulating complex passive sentences and linguistic edifices of technical nouns. In so doing, we have not appreciated that the message of Fowler et al, if taken seriously, should have profound consequences for the ways that we write our critical analyses.

If Halliday is correct, then we do not have to nominalise processes and use passives: there are always other possible options. With effort, we can try to avoid the standard habits of academic writing. This will not be easy. As I know from drafting this article, at each point passive impersonal clauses seem readily available; it is so easy to mobilize unthinkingly the available technical words, which, like 'nominalization', often end in 'ization'. It requires extra effort to turn the passives into actives, or to resist the technical vocabulary. When writers do so, they must fill in blanks, supply extra information and consider more carefully the social relations that they are describing.

Of course, it would be possible to go through this present article and point out all the passives that have been used (including this one) and so on. I could easily be accused of perpetrating the faults that I have accused others of committing. However, the tu quoque argument is not necessarily fatal (Walton, 1992). Failing to live up to one’s own 
standards is not, in itself, a refutation of those standards, just as one need not jettison all moral values because one has not lived a perfectly moral life. George Orwell stressed this in his essay 'Politics and the English Language'. He proposed six rules for writing that would help to avoid the lazy habits that were threatening, in his view, independent political thinking. The rules included avoiding jargon and passive sentences. Orwell admitted that he had probably failed to keep all his own rules, but that made the rules all the more, not less, necessary. Orwell commented that his rules might sound elementary; yet they 'demand a deep change of attitude in anyone who has grown used to writing in the style now fashionable’ (Orwell, 1946/1962: 156).

Given the influence of Orwell on Roger Fowler, it is appropriate that, in our own small way as critical analysts of language, we should aspire to change deeply our styles of writing. As the critical perspective becomes academically successful, so we need to become self-critically vigilant, lest by default we slip into the very discursive habits that we criticise in others. The message of critical analysis is that when speakers/writers start defending their own established ways of using language, they are often defending established social positions. One might predict, therefore, that as critical discourse analysis becomes established in the academic world, so its practitioners will be increasingly tempted to write in ways that are socially and intellectually problematic.

In the preceding analysis, I have stressed the dangers of 'nominalization'. One might, then, conclude that the argument expresses the need for 'De-Nominalization' and 'DeTechnologization', in order to combat 'Rhetorical Instantiation'. That, however, would exemplify just the sort of language to be avoided. We should not seek to create new linguistic entities, which, to paraphrase Fowler, we can parade like possessions. Perhaps, on the other hand, the argument could be reduced to something snappier and more widely understood: 'Power to the Verb'. It seems to encapsulate the underlying thought. But the slogan contains no verbs. Besides, we should be wary of slogans. Critical analysis requires clear thinking and clear writing. It will not be easy. Nor should it be.

\section{References}

Beaugrande, R. de (2006) 'Critical discourse analysis: history, ideology, methodology', Studies in Language \& Capitalism 1: 29-56.

Biber, D. (1992) 'On the complexity of discourse complexity: a multidimensional analysis’, Discourse Processes 15: 133-163.

Billig, M. (1996) Arguing and Thinking. Cambridge: Cambridge University Press.

Billig, M. (2000) 'Towards a critique of the critical', Discourse and Society 11: 291-292.

Billig, M. (2003) 'Critical Discourse Analysis and the rhetoric of critique', in G. Weiss and R. Wodak (eds) Critical Discourse Analysis. London: Palgrave Macmillan.

Billig, M. (2008) The Hidden Roots of Critical Psychology. London: Sage.

Bratlinger, E. (1997) 'Using ideology: cases of nonrecognition of the politics of research and practice in special education’, Review of Educational Research 4: 425-459. 
Chilton, P. (2005) 'Missing links in mainstream CDA: modules, blends and the critical instinct' in R. Wodak and P. Chilton (eds) A New Agenda in (Critical) Discourse Analysis. Amsterdam/Philadelphia: John Benjamins.

Clark, J.T. (2003) 'Abstract inquiry and the patrolling of black/white borders through linguistic stylization', in R. Harris and B. Rampton (eds) Language, Race and Ethnicity. London: Routledge.

Edwards, D. (2006) 'Discourse, cognition and social practices: the rich surface of language and social interaction', Discourse Studies 8: 41-50.

Edwards, D. and Potter, J. (1993) Discursive Psychology. London: Sage.

Fairclough, N. (1992) Discourse and Social Change. Cambridge: Polity Press.

Fairclough, N. (2003) Analyzing Discourse. London: Routledge.

Fairclough, N. (2005) 'Critical discourse analysis', Marges Linguistiques 9: 76-94.

Fowler, R. (1991) Language in the News. London: Routledge.

Fowler, R., Hodge, B., Kress, G. and Trew, T. (1979) Language and Social Control. London: Routledge

Goatly, A. (2007) Washing the Brain. Amsterdam/Philadelphia: John Benjamins.

Halliday, M.A.K. (1985) An Introduction to Functional Grammar. London: Edward Arnold.

Halliday, M.A.K. (2003) On Language and Linguistics. London: Continuum.

Halliday, M.A.K. and Martin, J.R. (1993) Writing Science. London: Falmer Press.

Kuo, S.-H. and Nakamar, M. (2005) 'Translation or transformation? A case study of language and ideology in the Taiwanese press', Discourse \& Society 16: 393-418.

Langacker, R.W. (1999) Foundations of Cognitive Grammar. Stanford University Press.

Lemke, J.L. (1995) Textual Politics. London: Taylor and Francis.

Malrieu, J.P. (1999) Evaluative Semantics. London: Routledge.

Marx, K. and Engels, F. (1846/1970) The German Ideology. London: Lawrence and Wishart.

Mautner, G. (2005) 'For-profit discourse in the nonprofit and public sectors', in G. Erreygers and G. Jacobs (eds) Language, Communication and the Economy. Amsterdam/Philadelphia: John Benjamins.

Maynard, S.K. (1999) 'On rhetorical Ricochet: expressivity of nominalization and da in Japanese discourse’, Discourse Studies 1: 57-81.

Moltmann, F. (2007) ‘Events, tropes and truthmaking’ Philosophical Studies 134: 363403.

Muntigl, P. (2002) 'Politicization and depoliticization: employment policy in the European Union’, in P. Chilton and C. Schäffnern (eds) Politics as Talk and Text. Amsterdam/Philadelphia: John Benjamins.

Muntigl, P. and Horvath, A. (2005) 'Language, psychotherapy and client change: an interdisciplinary perspective' in R. Wodak and P.A. Chilton (eds) A New Agenda In (Critical) Discourse Analysis. Amsterdam/Philadelphia: John Benjamins.

Orwell, G. (1946/1962) 'Politics and the English Language', in Inside the Whale and Other Essays. Harmondsworth: Penguin.

Potter, J. (2006) 'Cognition and conversation', Discourse Studies 8: 131-140.

Schroder, K.C. (2002) 'Discourses of fact', in K.B. Jensen (ed.) Handbook of Media and Communication Research. London: Routledge. 
Stenvall, M. (2007) 'The politics of fear: a critical inquiry into the role of violence in $21^{\text {st }}$ century politics', in A. Hodges and C. Nilep (eds) Discourse, War and Terrorism. Amsterdam/Philadelphia: John Benjamins.

van Dijk, T.A. (2001a) 'Multidisciplinary CDA: a plea for diversity', in R. Wodak and M. Meyer (eds) Methods of Critical Discourse Analysis. London: Sage.

van Dijk, T.A. (2001b) 'Critical discourse analysis', in D. Schiffrin, D. Tannen and H.E. Hamilton (eds) Handbook of Discourse Analysis. Oxford: Blackwell.

van Dijk, T.A. (2007) ‘Editor’s introduction’, in T.A. van Dijk (ed.) Discourse Studies. London: Sage

van Leeuwen, T. and Wodak, R. (1999) 'Legitimating immigration control: a discoursehistorical analysis’, Discourse Studies 1: 83-118.

Walton, D. (1992) The Place of Emotion in Argument. Pennsylvania State University Press.

Widdowson, H.G. (2004) Text, Context, Pretext. Oxford: Blackwell.

Wodak, R. (2006) 'Critical linguistics and critical discourse analysis', in J.-O. Östman and J. Verschueren (eds) Handbook of Pragmatics. Amsterdam/Philadelphia: John Benjamins.

Wodak, R. (2007) 'Pragmatics and critical discourse analysis: a cross-disciplinary inquiry’, Pragmatics \& Cognition 19: 203-225.

Yeung, L. (2007) 'In search of commonalities: some linguistic and rhetorical features of business reports as a genre’, English for Specific Purposes 26: 156-179. 